\title{
Solución del caso. Dolor abdominal y tumoración pancreática
}

\section{Viene de la página 8}

En la TCMD de abdomen con contraste endovenoso se observan imágenes quísticas parietales (Figura 2) y engrosamiento de la pared duodenal con estrechamiento de su luz (Figura 3). Además se logra visualizar a nivel del surco pancreaticoduodenal rarefacción de la grasa y dilatación del colédoco (Figuras 4 y 5).

El área del surco pancreático está comprendida entre la cabeza (medial), la serosa duodenal descendente (lateral), la tercera porción del duodeno / vena cava inferior (posterior), el colédoco en su segmento intrapancreático es parte del límite posterior, la primera porción duodenal y el antro gástrico (anterior) (Figura 6). ${ }^{1}$

La pancreatitis del surco es una patología poco frecuente, que se presenta como causa de pancreatitis aguda a repetición con estenosis duodenal. El término fue acuñado en 1973 por Becker y Bauchspeichel. ${ }^{2}$

Afecta predominantemente a varones entre $40 \mathrm{y}$ 50 años con historia de abuso de alcohol, aunque su etiología es incierta. ${ }^{3}$ El diagnóstico representa un desafío para el médico radiólogo, que frente a una masa de morfología laminar entre la cabeza pancreática y la segunda porción duodenal, que se presenta en la TCMD como una formación hipodensa (Figura 4) acompañada de engrosamiento concéntrico de la pared duodenal con estenosis de su luz, ${ }^{4}$ y presencia de formaciones quísticas en la pared del mismo 5 (Figuras 2 y 3), debe reconocer los múltiples diagnósticos diferenciales, como el carcinoma ductal pancreático y el carcinoma duodenal.

El tratamiento es principalmente conservador, con abstinencia alcohólica, analgésicos y reposo pancreático. Se espera una mejoría parcial de los síntomas ya que la alteración morfológica es permanente, siendo la ci- rugía $^{6-11}$ (duodenopancreatectomía) el tratamiento de elección si los síntomas no mejoran y ante las eventuales complicaciones. ${ }^{5}$

Figura 2. TCMD con contraste oral y endovenoso: imagen oval, hipodensa, compatible con quiste de la pared duodenal (circulo).

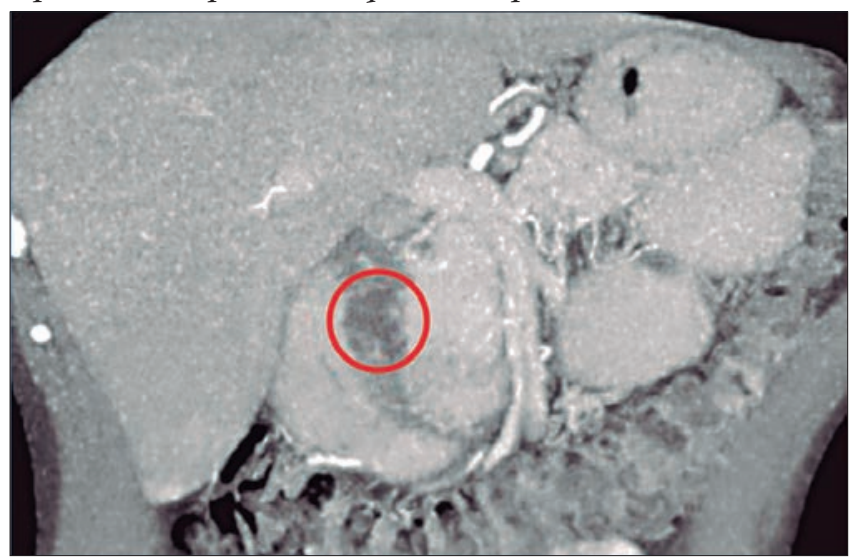

Figura 3. TCMD con contraste EV, corte axial, se marca el engrosamiento parietal del duodeno.

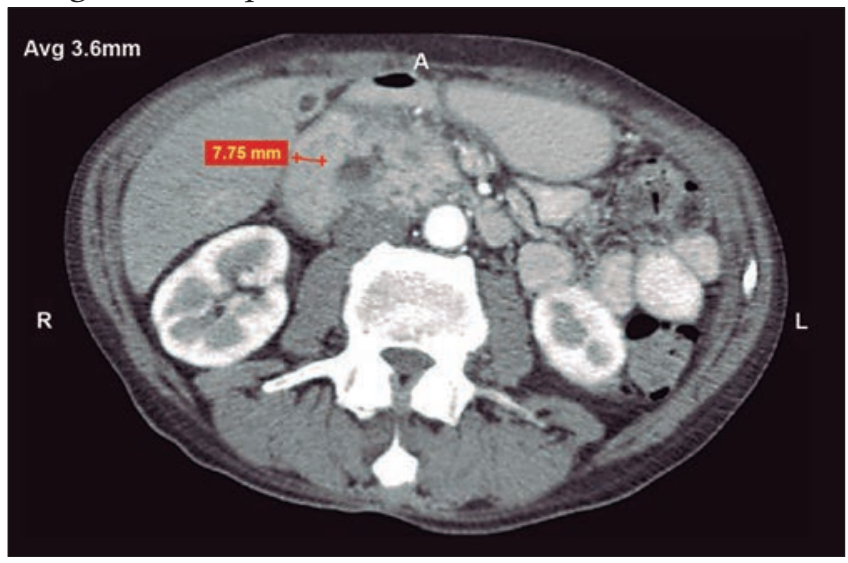


Figura 4. TCMD corte axial: se señala con flecha roja una zona con rarefacción de la grasa.

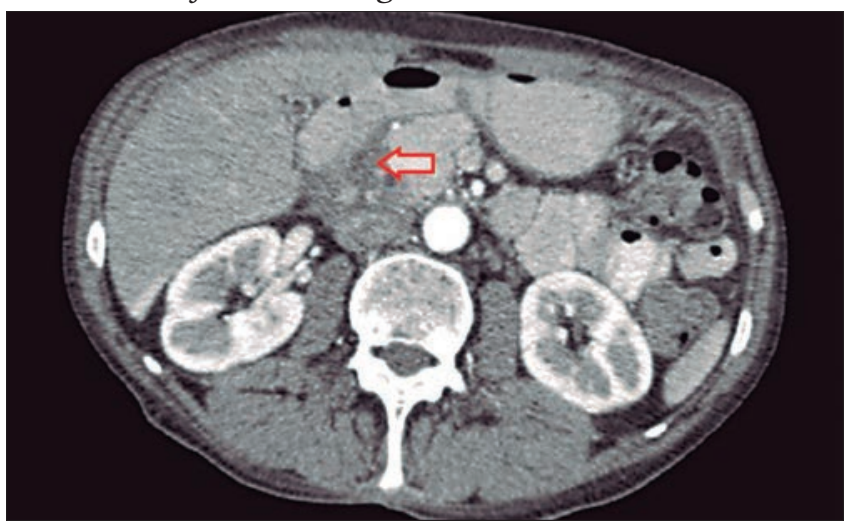

Figura 5. TCMD corte frontal: se marca la dilatación del colédoco.

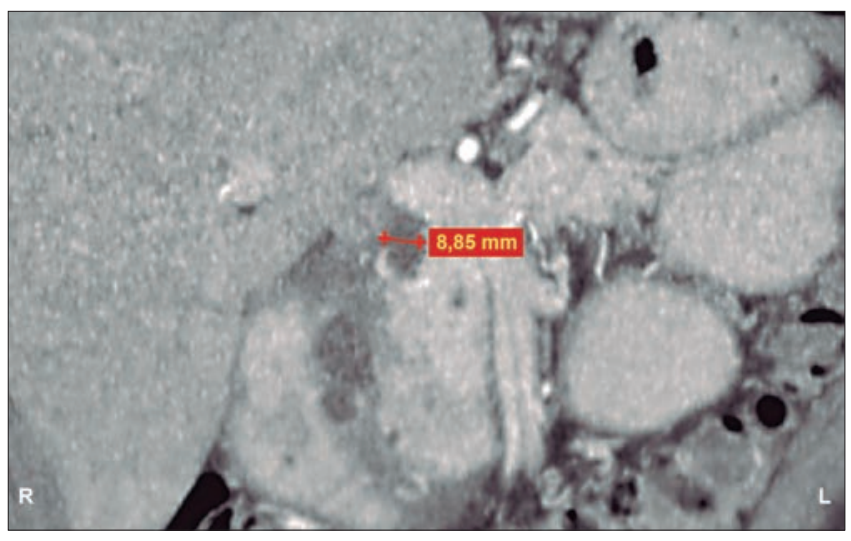

Figura 6. En este dibujo esquemático se señala con flechas rojas el surco entre el duodeno (Duo) y el páncreas (Panc) donde se produce la patología descripta.

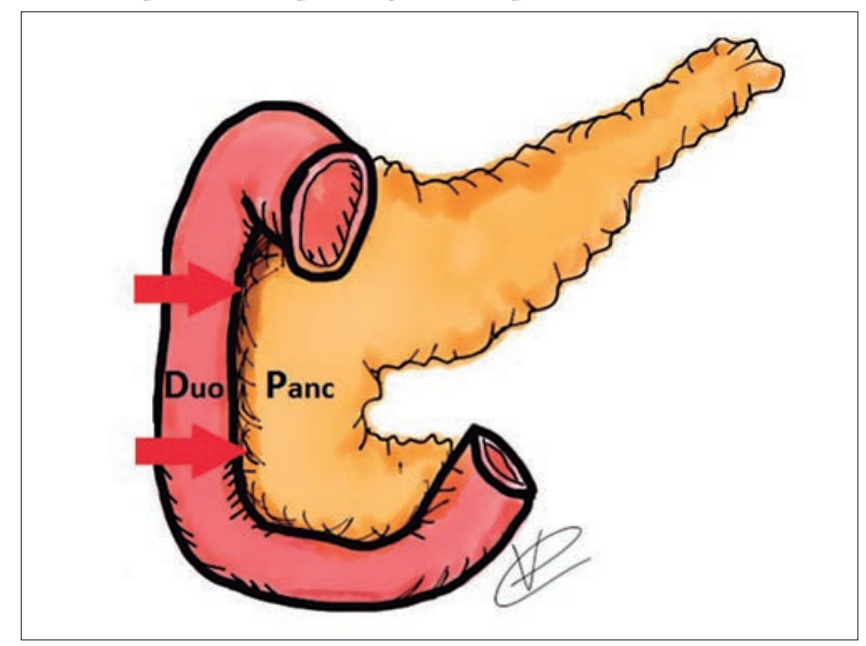

\section{Aviso de derechos de autor}

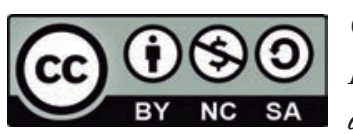

(C) 2021 Acta Gastroenterológica Latinoamericana. Este es un artículo de acceso abierto publicado bajo los términos de la Licencia Creative Commons Attribution (CC BY-NC-SA 4.0), la cual permite el uso, la distribución $y$ la reproducción de forma no comercial, siempre que se cite al autor y la fuente original.

Cite este artículo como: Polanco Amesquita VC, Larrañaga $N$, Clavijo González $C N$ y col. Dolor abdominal y tumoración pancreática. Acta Gastroenterol Latinoam. 2020;50(1):8, 83-4. https://doi.org/10.52787/bkel7000

\section{Referencias}

1. Normal anatomy and disease processes of the pancreatoduodenal groove: imaging features. AJR 2004; 183: 839-846.

2. Groove pancreatitis. Int J Pancreatol 1991; 10: 173-182.

3. Paraduodenal pancreatitis: a clinico-pathologically distinct entity unifying cystic dystrophy of heterotopic pancreas, para-duodenal wall cyst, and groove pancreatitis. Semin Diagn Pathol 2004; 21 : 247-254.

4. Groove pancreatic carcinomas: radiological and pathological findings. Eur Radiol 2003; 13: 1679-1684.

5. Cystic dystrophy of the duodenal wall in the heterotopic pancreas: radiopathological correlations. J Comput Assist Tomogr 2000; 24: 635-643.

6. A special form of segmental pancreatitis: groove pancreatitis. Hepatogastroenterology 1982; 29: 198-208.

7. Normal anatomy and disease processes of the pancreatoduodenal groove: imaging features. AJR 2004; 183: 839-846.

8. Groove pancreatitis: report of a case and review of the clinical and radiologic features of groove pancreatitis reported in Japan. Intern Med 2002; 41: 537-542.

9. Paraduodenal pancreatitis: a clinico-pathologically distinct entity unifying cystic dystrophy of heterotopic pancreas, para-duodenal wall cyst, and groove pancreatitis. Semin Diagn Pathol 2004; 21 : 247-254.

10. MRI of groove pancreatitis. J Comput Assist Tomogr 1998; 22: 651-655.

11. Duodenopancreatectomy for cystic dystrophy in heterotopic pancreas of the duodenal wall. Gastroenterol Clin Biol 2006; 30: 24-28. 